\title{
A Emilia Pardo Bazán, de Leopoldo García Ramón. Sociabilidad literaria y cooperación en La España Moderna*
}

\author{
Dolores Thion Soriano-Molla \\ (UNIVERSITÉ DE PAU ET DES PAYS DE L'ADOUR) \\ dolores.thionsoriano-molla@univ-pau.fr
}

(recibido setembro/2011, revisado outubro/2011)

RESUMEN: Las tres cartas que Leopoldo García Ramón remitió a Emilia Pardo Bazán, entre 1885 y 1889, son testimonio vivo del papel que la escritora ejerció como mediadora intercultural. Las relaciones amistosas que ella mantuvo con el escritor sevillano afincado en París propiciaron un intercambio de favores mutuos y de gestiones que redundaron en el lanzamiento de la revista La España Moderna (1889), propiedad de José Lázaro Galdiano. En dicha empresa, Doña Emilia fue algo más que la oculta consejera y, si las circunstancias hubiesen sido distintas, probablemente hubiese asumido públicamente el cargo de directora de tan importante revista.

PALABRAS CLAVE: Correspondencia, sociabilidad literaria, mediación cultural, Emilia Pardo Bazán, Leopoldo García Ramón, José Lázaro Galdiano, La España Moderna.

ABSTRACT: Three letters that Leopoldo García Ramón sent to Emilia Pardo Bazán between 1885 and 1889 , clearly show the role that she played as a cultural mediator. This relationship with the Sevillian writer who lived in Paris, led to an exchange of favours and resolved business issues that led to the launching of the journal *La España Moderna *(1889), owned by José Lázaro Galdiano. In this endeavor, Doña Emilia was much more than behind the scenes counsel, and perhaps, if the circumstances had been different, she would have publicly assumed the role of director of such an important journal.

KEY WORDS: Letters, literary sociability, cultural bridging, Emilia Pardo Bazán, Leopoldo García Ramón, José Lázaro Galdiano, La España Moderna.

La reconstitución de las relaciones de sociabilidad profesional siempre es un campo de interés para conocer la influencia que una personalidad pública puede ejercer $y$, a la inversa, el reconocimiento que de los demás merece o la autoridad que los otros le atribuyen. No es que siempre ello conlleve criterios de calidad literaria o determine la entrada de un escritor en el canon literario, temas que ahora no vienen al caso, pero sí nos permite comprender el sistema de relaciones que directa o indirectamente entreteje un escritor y que influye en la vida literaria, a veces mucho más allá de lo estrictamente extratextual.

Estos aspectos adquieren particular relevancia respecto de Emilia Pardo Bazán y en el contexto decimonónico dominante en el que se tuvo que desenvolver, sobre

\footnotetext{
* Este estudio parcial se lleva a cabo dentro del proyecto "Ediciones y estudios sobre la obra literaria de Emilia Pardo Bazán” (Ref. FFI 2010-18773) financiado por el Ministerio de Ciencia e Innovación (2011-2014).
} 
todo habida cuenta de las dificultades con las que siempre tuvo que bregar para adquirir nombradía y lograr que se le atribuyeran responsabilidades públicas en tanto que mujer escritora. La curiosidad intelectual, la entrega y el activismo de la escritora gallega son rasgos que solemos citar como manidas etiquetas; éstas se dan por asumidas sin llegar a calibrar, de manera efectiva, el alcance y los límites de su quehacer o de su capacidad de decisión, de su margen de maniobra y del sesgo de sus gestiones; en suma, el modo de actuar de una mujer; voz de per se instalada en la diferencia individual en el seno de una comunidad cultural en mayor o menor grado uniforme. El aquilatamiento de documentación privada de Emilia Pardo Bazán, en particular de su correspondencia, está permitiendo afinar y conocer en mayor profundidad el calado de la actividad de la escritora y, en definitiva, el calibre de su personalidad.

Las cartas que en el presente trabajo editamos son tres, remitidas por Leopoldo García Ramón a Doña Emilia desde París en 1885 y en 1889. Su originalidad reside precisamente en ser autógrafos que la escritora recibió, puesto que son pocos los que en esta dirección del intercambio epistolar se han localizado hasta la fecha. Como suele ser habitual, estas tres cartas no son más que leve muestra de lo que tuvo que ser un nutrido epistolario; ya lo pudimos observar al estudiar la correspondencia que Leopoldo García Ramón envió a Edmond Goncourt, haciendo las veces de intermediario y agente de Doña Emilia en París (Thion Soriano-Mollá, en prensa). En ellas, afloraban también algunos temas que se entrecruzan con estas cartas, en particular, respecto de La España Moderna.

Bien se sabe que Emilia Pardo Bazán contribuyó activamente en el lanzamiento de las empresas culturales de José Lázaro Galdiano, la editorial La España Moderna y la homónima revista. Mentora, consejera, gestora, escritora y traductora, estas fueron algunas de las funciones que ejerció la escritora gallega en 1889 para ayudar a su amigo en tales innovadores y arriesgados proyectos. Bien se sabe asimismo, aunque de manera bastante imprecisa, que la escritora utilizó sus propias relaciones personales para introducir a José Lázaro en los círculos intelectuales y aristocráticos madrileños, si bien los límites de su actuación son más anotados que fehacientemente delimitados. Tal vez si se lograse documentar las numerosas gestiones que ella realizó en aras de aquellos ambiciosos proyectos, o si al menos se pudiese hacer acopio del importante número de cartas que Emilia Pardo Bazán escribió en nombre de o para Lázaro Galdiano -sobre todo porque no hablaba idiomas- se podría evaluar mejor su contribución en el feliz alumbramiento de aquellas empresas. En las cartas que reproducimos y a través de la voz de Leopoldo García Ramón se puede documentar el peso que tuvo la escritora en el lanzamiento de La España Moderna y la autonomía de la que gozó en la elaboración de los primeros números de la revista de Lázaro.

¿Quién era Leopoldo García Ramón? ¿Por qué formaba parte del círculo de relaciones profesionales de Emilia Pardo Bazán? Se dispone de poca información sobre este escritor sevillano, homónimo del pintor valenciano también residente algunos años en París con quien a veces se le confunde. Leopoldo García Ramón $(1845-i$ ?) destacó desde joven por su dedicada entrega al estudio de la literatura. Era 
autodidacta. Se jactaba con ironía de no ser "siquiera bachiller, no he frecuentado las aulas, no puedo decir: estudié con Periquito o con Manolito, y esto viene a significar que no he estudiado con nadie. Yo no sé nada, no tengo erudición" (García Ramón, "Cartas de París", Revista contemporánea, 30 de agosto de 1886: 387) y hacía asimismo burla de su anonimato o de la vulgaridad de su nombre:

No tengo tampoco la autoridad de un nombre presentable; usted ya ve: Ilamarse García es lo mismo que llamarse D. Nadie, es de lo más vulgar, y en Madrid sólo, pasan de quinientos los Garcías; Ramón, ya es algo más original, como nombre convertido en apellido; pero es también muy plebeyo; los franceses Ilaman así á las escobas de ramiza, y en España es un apellido que se come el ganado (García Ramón, "Cartas de París", Revista contemporánea, 30 de agosto de 1886: 387).

Había empezado a escribir temprano. "A los doce años", declaraba él recurriendo a los estereotipos regionales, "ilos andaluces somos tan precoces! y he seguido escribiendo sin poderme contener". Pero, como precisaba, escribir no quiere decir publicar. Su primer libro, El arte de fumar, salió a la luz tardíamente, en 1881, en la parisina editorial Garnier. Hacía cinco años que Leopoldo García Ramón había fijado su residencia en París. Su fuente principal de ingresos procedía de su cargo de negociante en la empresa farmacéutica Maison Crimault, a la que alude en la primera carta, por lo que las Letras ocuparon posición secundaria.

Si por algo se le ha ido recordando a Leopoldo García en los últimos años es por el tratado El arte de fumar: Tabacología universal (1881), el cual ha sido reeditado en sucesivas ocasiones (Valencia, s f, San Sebastián, 2000 y Valladolid, 2008). No sólo este tema aunó los intereses del librepensador con Doña Emilia, también lo hicieron otros asuntos entonces de moda, tales como El magnetismo, sonambulismo y espiritismo: estudios curiosos y filosóficos (circa 1880), o los campos ya específicamente literarios como la traducción, la crítica y la estética literarias.

En el ámbito del periodismo, Leopoldo García Ramón hizo sus primeras armas en revistas de primera plana: Revista Contemporánea, La España Moderna, Revista de España y El Globo; entre 1886 y 1890 aproximadamente. En la última década del siglo toda su actividad decayó prácticamente de manera súbita. Tal vez la accidental muerte de su único hijo -en el torpedero 110- en 1889 (Pardo Bazán, "Entre paréntesis. A una cara memoria", El Liberal, 25 de abril de 1889: 1) influyese en ese distanciamiento, ya que a principios de siglo toda su producción se limita a la traducción de las Obras Completas de Maupassant. Cabe pensar, por otra parte, que las bajas retribuciones que la prensa proporcionaba le indujeron a dejar de contribuir en las cabeceras españolas. Desde París, colaboró de manera asidua en El Correo de Ultramar durante muchos años y en La Revista Puertorriqueña de Manuel Fernández Juncos (cartas segunda y tercera).

Frente a sus ensayos y obras de creación literaria Seres humanos (1884), Dos amores (1886), Los extranjeros en París. La Nena (1891), y Filosofía de bolsillo, el arte de vivir (1893), destaca su intensa labor como traductor y editor de obras importantes, tales como las de Calderón, las de Ruiz de Alarcón y las de Quintana 
para las editoriales francesas Hachette, Garnier y Charpentier, las cuales editaban obras en castellano para poder implantarse en los mercados hispanoamericanos. Asimismo, dio a conocer en España las obras de Buffon, Andersen, La Fontaine, Maupassant, Belot, Bocaccio y Radau, con traducciones de propia mano.

Los primeros contactos entre Leopoldo García Ramón y Emilia Pardo Bazán datan de 1884, cuando él le pidió a la escritora que avalase con un prólogo su primera novela, Seres humanos. Aun cuando ella no "tuviese el gusto de conocer á usted, usted tuvo la cortesía de pedirme unos cuantos renglones, narrándome su irresistible vocación de novelador y sus preferencias hacia la escuela de la verdad en el arte, cuyos principios tanto se discuten en la actualidad" (García Ramón, 1884: 5). Pese las imperfecciones que Doña Emilia desveló en lo que fue una carta a modo de exordio, el interés mayor de la escritora por Seres humanos residía esencialmente en factores extraliterarios; a saber, el reconocimiento de su autoridad por parte del neófito novelista y el hecho de que aquel texto procediese del dorado París. Por ello, sabiendo que las peticiones denegadas eran numerosas, la escritora justificó sus atenciones porque le parecía "justo informar al público de como esta escritora residente en el fin del mundo (FINISTERRAE) encabeza con su prosa la primer obra de un novelista que se estrena en el centro del orbe civilizado, en París. Nosotros lo sabemos, pero el lector lo ignora" (García Ramón, 1884: 5) ${ }^{\mathrm{I}}$. Merced al prólogo de Seres humanos. Estudios de mujer y al prurito de europeísmo de Doña Emilia, se inició el itinerario de lo que sería una larga amistad. Desde entonces, García Ramón le remitió sus obras para contar con su juicio esclarecido y sus doctos consejos porque ella era "su conductora en este viaje" (Carta de Leopoldo García Ramón a Narcís Oller del 9 de octubre de 1886) en la composición literaria.

Cuando Pardo Bazán realizó su primer viaje a París, en 1885, conoció personalmente a su prologado. Sus relaciones se consolidaron y el intercambio de noticias, libros o servicios mutuos, como los que esta correspondencia trasluce, fue continuo. Entre Leopoldo García y Emilia Pardo Bazán se fueron estableciendo lazos de estrecha amistad, a tenor de las declaraciones cariñosas que están desperdigadas por sus respectivos artículos. De hecho, en estos términos se dirigía Leopoldo García a José Lázaro Galdiano unos años después:

le agradezco las frases amables que V. me dedica, pero no se fíe de Doña Emilia que ve en mí muchos méritos... por venir. En una sola cosa tiene tal vez razón y es que soy servicial para quién lo merece; por lo tanto disponga V. a su antojo de mí, que sus deseos quedarán cumplidos, si está en mi poder realizarlos (Carta de Leopoldo García Ramón a José Lázaro Galdiano, 1 de febrero de 1889).

Leopoldo García ayudó a Doña Emilia a introducirse en los círculos literarios parisinos que él mismo frecuentaba, le dedicó su novela Dos amores (1886) y tradujo Bucólica al francés (1887). Una vez consolidada la amistad, se encargó además

\footnotetext{
I Las opiniones favorables de Emilia Pardo Bazán fueron recabadas en "Seres humanos", El Día, 14 de febrero de 1884
} 
de otros asuntos crematísticos, como era la compra de té para la escritora (carta tercera).

Ella utilizó su Nuevo Teatro Crítico para dar a conocer las obras del escritor expatriado en España. Tras aquel primer prólogo de Seres humanos. Estudios de mujer, Pardo Bazán fue reseñando en su revista las obras de su amigo. En mayo de 1891 le dedicó una reseña a su novela Los extranjeros en París. La Nena. Escudándose tras la imparcialidad crítica, la consideró como una obra naturalista algo trasnochada, a pesar de la seriedad, esmero y honradez del novelista. Justificaba con argucia la escritora:

Para hablar de este libro me cohíbe la antigua amistad que profeso a su autor. Cualquier elogio, en mi pluma, puede interpretarse como tributo pagado a un sentimiento noble, pero que no tiene nada que ver con la crítica, aunque no suele descarriarnos tanto como el odio. Los que lean La Nena se convencerán de que voy a pasarme de severa, por temor de caer en interesada benignidad ("Juicios cortos" [mayo de 1891]: Nuevo Teatro Crítico, : 86).

Más benevolente se mostró Doña Emilia respecto de Filosofía de bolsillo. El arte de vivir, también reseñada en su revista. Ella compartía la actitud crítica del escritor sevillano en dicha obra, por ser "protesta repleta de buen sentido contra el pesimismo al uso" ("Letras y libros" (30 de diciembre de 1893): Nuevo Teatro Crítico, 286). Según García Ramón, el pesimismo se estaba generalizando en tanto que pose burguesa, sin tener nada que ver con los caracteres sensibles, dominados por "la melancolía y el dolor moral, el descontento profundo, la renuncia schopenhaueriana y la persuasión de la infinita vanità del tutto", propio de las "almas selectas", según suscribía la escritora en el artículo citado de revista ("Letras y libros" [30 de diciembre de 1893]: Nuevo Teatro Crítico, 286) ${ }^{2}$.

En última instancia, como documenta la primera de las cartas, correspondiente al 6 de abril de 1885, Leopoldo García Ramón esperaba que Emilia Pardo Bazán intercediese en su favor en asuntos editoriales en Madrid, ya que sus trabajos de crítica y creación siempre los realizó en la lengua materna. Las dos cartas siguientes se centran en el proyecto de La España Moderna, donde Doña Emilia le invita a colaborar. La primera de ellas data del 15 de diciembre de 1988, poco antes de que saliese a la luz la revista. Las opiniones que Leopoldo García transmite en ella a Doña Emilia son entusiastas y detalladas. Además, se pueden columbrar en ellas las numerosas confidencias que la escritora le había hecho respecto del perfil de La España Moderna y su futura difusión, pero también sus sondeos e inquietudes en torno a su relación con Galdós ante el consumido affaire con Lázaro. "No sé nada de lo de Galdós. No salgo de mi Revista y mi novela. Dígame V. lo ocurrido" (Carta segunda), le contestaba al respecto su amigo, quien a todas luces estaba al corriente de la vida amorosa de la escritora (Thion Soriano, 2003). La tercera carta, escrita dos meses después, prosigue en la misma línea con el tema de la revista.

\footnotetext{
${ }^{2}$ Véase asimismo: Zaravel (15 de mayo de 1891): "Notas sueltas", Revista Contemporánea, 243-245; quien reproduce la reseña de Emilia Pardo Bazán.
} 
En invierno de 1885, era la primera vez que Emilia Pardo Bazán pasaba unos meses de estudio en la capital francesa. La amistad entablada con el compatriota español y su esposa Constante debieron amenizar alguna velada de la escritora y favorecer algunos de sus objetivos de índole literaria, en especial su introducción en el granero de los Goncourt. Los asuntos que Leopoldo García planteaba en esta carta de despedida -la víspera del regreso de Doña Emilia a Madrid- hacen las veces de recordatorio. Las consignas del escritor son precisas. Su deseo de estar presente en las Letras españolas y de dar a conocer su producción creativa en tierra patria le hacía confiar en la habilidad gestora de la escritora. Esperaba que ella le ayudase a publicar en la prensa un artículo mensual, "sobre letras y artes, gratis" (Carta primera). Seguramente Doña Emilia le había convencido de la necesidad de dar a conocer en España la literatura francesa, puesto que lo único que solicitaba Leopoldo era "el derecho de poder anunciar a los editores franceses que escribo esos estudios, por si me envían los tomos, lo que me parece justo" (Carta primera). La propuesta iba dirigida a un periódico de amplio alcance, El Imparcial, en el que Doña Emilia colaboraba desde 1883, pero el proyecto no cuajó. La firma de Leopoldo García Ramón no aparece ni en El Imparcial ni en Los Lunes de El Imparcial; tampoco corresponden sus iniciales a las del supuesto corresponsal en París "M.", e incluso si barajamos la posibilidad del seudónimo, sabemos que el carácter político de la sección "Alrededor del mundo" firmada por el corresponsal en París no era de su interés. Cuando doña Emilia le propuso dicho tema para La España Moderna, su respuesta fue contundente: "Abomino el género, soy bastante acerbo en él y tengo ideas que no cabrían en revista dirigida por V" (Carta segunda).

Las lagunas en este intercambio epistolar nos impiden comprobar si fue Doña Emilia quién introdujo a Leopoldo García en la Revista Contemporánea, tribuna en la que él empezó a publicar en agosto de 1886. Con sus artículos esperaba contribuir -a imagen de la escritora, según declaraba abiertamente- a la difusión en España de las novedades artísticas, literarias y científicas extranjeras en las secciones "Revista crítica" y "Cartas de París" para dar "mayor variedad posible a nuestra revista", anunciaba su director, Rafael Álvarez Sereix, el 10 de agosto de 1886.

Puesto que la amenidad y la variedad fueron objetivos que tanto Pardo Bazán como Lázaro persiguieron para La España Moderna, tres años después, ella le propuso la composición de ese mismo tipo de crónica (Carta segunda). El librepensador cambió entonces de prioridades y de exigencias; prefirió el pago a la nombradía cuando Doña Emilia le presentó epistolarmente a José Lázaro, haciendo alarde de su seriedad y su solvencia financiera (Carta segunda). A pesar de que Leopoldo García Ramón disentía con la escritora respecto de la anonimia en la prensa -incluso para una crónica parisiense-, acabó claudicando:

Por lo demás, no tuerzo el gesto ni poco ni mucho; en esto no me ha calado $\mathrm{V}$. Creo empero haberle dicho que la opinión del público me importa tres pitos y sólo estimo la de las personas que saben leer y apreciar. Tanto es así que, si no fuera por la especie de coquetería que entraña, ni las novelas firmaría. Como V. comprende, 
si mis artículos salen bien y gustan, el gremio literario sabrá perfectamente quién los escribe y eso me basta. Estoy pues dispuesto á escribir sin firmar (Carta segunda).

Gratis y en el anonimato. Pocos escritores se hubiesen prestado al juego por tratarse de Doña Emilia, aquel "prodigioso cerebro" de quien "puede esperarse todo" (Carta segunda). El incondicional admirador insistía, cuando todavía La España Moderna estaba en ciernes, ante su propuesta de colaboración: "En cuestión metálica, precio, pago, etc. como V. quiera ${ }^{3}$; lo que yo deseo es estar con V. contribuir á una obra interesante y nada más" (Carta segunda). Sin embargo, ese no era su criterio habitual. Leopoldo García no aceptó las treinta pesetas que Josep Yxart le proponía en La Publicidad y en La Ilustración; como tampoco las de José Lázaro cuando éste, en febrero de 1899, tomó las riendas en estos asuntos; sobre todo porque había cobrado -como todos los amigos de Doña Emilia- 50 francos ${ }^{4}$ (Carta tercera) por su primera colaboración, "Notas bibliográfícas. La novela española en Francia", en febrero de 1889 (Asún, 1981-82; Villapadierna, 1983).

A ese respecto, son de singular curiosidad las anotaciones que Doña Emilia incluyó en los márgenes y a pie de páginas de la segunda carta. Dichas notas hacen alusión a algunos aspectos internos fundamentales, tales como la dirección de la revista, las retribuciones de los artículos, la sección parisina y sus características, o aspectos estructurales, como eran los "abonos y venta", que ella valora por su utilidad.

De ser sinceros, esos breves comentarios que ella fue dando a Lázaro, antes de transferirle la carta de Leopoldo García Ramón, dan cuenta de ciertos desajustes entre la escritura y la interpretación de los intercambios, entre la mirada que cada corresponsal vierte del otro y su verdadera opinión; en particular, las de Don Leopoldo como incondicional admirador y autor de estos autógrafos; las de Doña Emilia como correctora de las declaraciones de Don Leopoldo, con supuesta complicidad con Lázaro. De todos estos asuntos, Ilama en particular la atención el referido a la elección del nombre que debía aparecer a la cabeza de la revista.

Si es cierto, como siempre se ha afirmado tomando como testimonio las cartas de Doña Emilia a Benito Pérez Galdós, que la escritora se presentaba como "auxiliar" en la dirección de la revista (nota primera) a mediados de diciembre de 1988, es curioso que necesitase unas semanas antes pedirle al amigo de confianza "su opinión" respecto de dicho cargo. La respuesta de Leopoldo García Ramón es lúcida y pragmática. Frente a un nombre desconocido como era el de Lázaro, más acertado parecía el estratégico consejo de don Leopoldo, quien abiertamente le contestaba:

\footnotetext{
3 Doble subrayado original del autor.

4 José Lázaro le proponía, por ejemplo: "Si V. se decide a escribirla yo le ofrezco el maximum que puedo dar, treinta pesetas y los números que V. necesite para los editores, etc.

Comprendo lo justo de las razones que me da en su carta del 17 de Diciembre; V. hará en vista de mi nueva proposición lo que más le convenga”, Carta de Leopoldo García a José Lázaro Galdiano, París, 1 de febrero de 1889. El mismo tipo de comentario aparece en la correspondencia inédita dirigida a José Yxart, a quién solicitó para que le introdujese en La Publicidad y en La Ilustración.
} 
Creo que debería V. poner su nombre al frente, pues tiene suma importancia para el éxito y la venta. Claro que le cae a $V$. encima una responsabilidad que no tiene contentándose con ser oculta inspiradora, pero un nombre desconocido al frente de una publicación nueva no da ninguna garantía al lector (Carta segunda).

¿Realmente había deseado Doña Emilia no asumir esa responsabilidad cuando tanto estaba trabajando en la confección de la misma? ¿Quería José Lázaro acaparar la dirección de la revista, por ser el propietario, sabiendo cuáles eran sus aportaciones y su nombradía? La información que proporcionan las cartas conservadas no nos permiten dar respuesta a estos interrogantes. Ahora bien, si buscaron escritores de primera fila para atraer potenciales lectores, lo lógico, como sostenía Don Leopoldo, es que el director avalase la revista merced al reconocimiento público. El voluntario ocultamiento de Doña Emilia ¿fue decisión tardía? Tal vez el desarrollo del célebre affaire amoroso (Thion: 2003) y la necesidad de guardar públicamente las apariencias les condujera a tomar dicha decisión.

Recordemos que La España Moderna nació, según declaraba la misma escritora a Don Benito, del empeño de José Lázaro en "marcharse de Barcelona y vivir donde pudiera verme" (Pardo Bazán, 1978: 96). Ella aseguraba a Galdós, intentando ganarse su perdón, que Lázaro con la revista "acercaba las órbitas y creaba una comunidad de trabajos y pensamientos" (Pardo Bazán, 1978: 96), para la que ella realmente había ofrecido su "cooperación decidida y completa, que no he escatimado" (Pardo Bazán, 1978: 97), sobre todo porque "respecto a intereses, ¡ni una palabra se habló!" (Pardo Bazán, 1978: 97) y porque el joven Lázaro, enamorado de ella, hubiese querido:

mucho de ganar mucho también, para poner a mi disposición lo que ganase. Pero como yo no había de admitir sin el precio de mi trabajo, en concepto de colaboradora, y en otro concepto las delicadezas y obsequios que prescribe la galantería tratándose de una mujer, y nada más, de ahí que toda esta cuestión de Revista sea aparte de la de mi emancipación y no tenga nada que ver con ella (Pardo Bazán, 1978: 97)

Si a tenor de estas declaraciones, la colaboración había sido definida en términos tan claros, ¿por qué pedirle consejo a García Ramón al respecto? Aun cuando hubiese deseado, con toda legitimidad, que se reconociese su trabajo públicamente ya fuese de directora o de consejera, no hay que olvidar que Galdós le reprochaba a doña Emilia que La España Moderna le estaba generando ataduras y compromisos que no eran de su agrado. Aun así, ella antepuso el respeto de los compromisos profesionales para que "nadie resultase arruinado por una empresa acometida por acercarse a mí, y sobre que a los ojos del público, que no está en interioridades, esto me dejaría en mal lugar" (Pardo Bazán, 1978: 97).

Por otra parte, como precisa la cita más extensa antes reproducida, en este periodo Emilia Pardo Bazán deseaba independizarse económicamente de sus padres y vivir de su propio quehacer mercantilizando sus actividades. De ello también había hablado a Narcís Oller, a quién informó en carta privada a que iba a "trabajar algo -no sé qué- para la gran revista que funda nuestro amigo Lázaro. Por la señas va a ser una publicación notabilísima y única en su género en España" (Carta de Emilia Pardo 
Bazán a Narcís Oller del 24 de diciembre de 1888). En última instancia, el hecho de que poco tiempo después, en enero de 1891, bajo pretexto de seguir el modelo de Feijoo, Doña Emilia se decidiese a lanzar una revista cultural también abierta a Europa, pero unipersonal, redunda en su interés en definir el alma de una tribuna y dirigirla con total libertad.

Respeto de los otros asuntos que estas cartas presentan, destaquemos la organización de las redes de difusión de la revista en París, para lo cual, ejerció un generoso papel Leopoldo García, tanto en las reseñas de otras revistas, como en la librería de Albert Savine (carta segunda).

El escritor sevillano siguió colaborando con La España Moderna en la búsqueda de un agente comercial que se encargase de recabar anunciantes para la revista. En estas cuestiones, pronto cedió la palabra Doña Emilia a José Lázaro, quién trató todos estos asuntos mercantiles directamente, desde finales de febrero de 1889. Ahora bien, como se puede observar en estas cartas, durante el lanzamiento de la revista fue ella quien fijó las directrices del contenido y de las colaboraciones, consciente de la calidad del trabajo de las firmas solicitadas y su notoriedad pública. No obstante, también se comportó como fiel amiga y supo corresponder a Leopoldo García con responsabilidad. Con él se mostró directiva y le propuso una colaboración mucho más modesta de lo que él sobrentendió, la de una crónica parisina y no la de artículos de mayor calado en el cuerpo de la revista, como fueron los relacionados con la crítica literaria. Pese a rendir cuentas a José Lázaro como bien demuestran las notas de las cartas, Emilia Pardo Bazán gozó de un amplio margen de libertad en estos momentos claves, por ser los fundacionales, de La España Moderna.

A través de la generosa colaboración de Leopoldo, Lázaro intentó conferir a la revista una mayor proyección en Francia. Una década después, el escritor afincado en París seguía haciendo las veces de agente literario del editor, e incluso, en 1891, asistía al editor en la búsqueda de obras amenas y exentas de derechos de autor para traducirlas y publicarlas. En 1900, Lázaro volvió a proponerle aquella vieja "Crónica parisiense" 5 que antes del parto de la revista, había ideado Doña Emilia (carta segunda). Pero, todo ello, es otra historia y son también otras cartas.

Las relaciones de sociabilidad de Emilia Pardo Bazán fueron más variadas e intensas de lo que hasta ahora se ha podido documentar. A través de un juego de imágenes en espejos, se perfila la fuerte personalidad de Doña Emilia, quien suscitó no sólo animadversión, sino también fieles e incondicionales amistades, como fueron la de Leopoldo García o la del mismo José Lázaro. Por su capacidad de trabajo y su tesón logró impulsar, tal vez en mayor medida de lo que se suele reconocer al atribuirle el cargo de mera consejera, las empresas culturales de La España Moderna. La cooperación de las personas que por estas tres cartas desfilan ponderan el papel de nuestros protagonistas en tanto que promotores del conocimiento de la literatura española en Francia y de la francesa en nuestro país.

\footnotetext{
5 Unos meses antes le publicó Lázaro un artículo sobre uno de los íntimos amigos del escritor sevillano como homenaje póstumo: “Escritores americanos. Don Juan de Montalvo" (abril de 1899): La España Moderna, 99-121.
} 


\section{Carta 1}

Membrete ${ }^{6}$.

París, à 6 de Abril -85.

Mi querida amiga: en este mismo instante, son las doce, recibo una carta de mi principal que me ordena ir al Havre para el arreglo de un asunto. Pienso estar de vuelta mañana mismo, pero no sé si à tiempo de ir a despedirla a la estación. Caso de no, hasta el próximo invierno.

Adjunto le remito à V. el artículo que afortunadamente pude hacer ayer; como está hecho con alguna precipitación, si encuentra V. algún gazapo, de le V. un linternazo. He aquí lo que desearía. Respecto del artículo uno al mes, sobre letras y artes, gratis, pero con el derecho de poder anunciar à los editores franceses que escribo esos estudios, por si me envían los tomos, lo que me parece justo. Dos ejemplares de cada número que contenga un artículo mío, uno para mí, otro para el editor.

Respecto de la novela 7,30 ejemplares si he de dar yo de ellos à los críticos madrileños; sino, 10 ejemplares. Si no puede un tanto por tomo vendido, sea lo que fuere, por salvar al principio; si es imposible como V. lo arregle. Ya me lo dirá V. con todos los detalles necesarios y así mismo a quién debo enviar el manuscrito. Se lo di à un impresor amigo, en Corbeil, y aún no me lo ha devuelto: aunque solo quería yo saber si llegaría a formar 300 páginas caso de que lo envíe hoy ó mañana antes de las 3, ¿quiere V. Ilevárselo? Si acepta, lo que me tranquilizaría, pues confiarlo al correo, aunque vaya certificado me asusta, respóndame $\mathrm{V}$. una palabra, que mi tía leerá la carta y lo mandará si lo ha recibido.

Es todo lo que por ahora se me ocurre.

Aunque no, me falta suplicarle à $\mathrm{V}$. que à lo menos una vez al mes tenga $\mathrm{V}$. la condescendencia de decirme como sigue de salud y de trabajo.

Mis recuerdos amistosos a su señora madre, un beso a la finísima piel del hermoso Jaime (sic), y un buen apretón de manos de su sincero

\section{García Ramón}

Otro apretón a Daniel López ${ }^{8}$ si lo ve V. por Madrid.

Si acepta el Imparcial, mi próximo artículo será Germinal.

\footnotetext{
6 Membrete: Siempre, cráneo, pluma ave, pluma estilográfica y dos golondrinas en el margen superior izquierdo.

7 Se estaba refiriendo a su novela Dos amores (1886): París, Imp. A. Lanier.

${ }^{8}$ Daniel López fue compañero de Doña Emilia en sus clases de alemán y griego. Era de origen humilde, por lo que trabajó de maestro en la Institución Libre de Enseñanza gracias al apoyo de la escritora y de Francisco Giner de los Ríos (Faus, 2003, I: 241-245). Daniel López realizó traducciones del inglés, en particular de libros científicos e históricos. Doña Emilia le dedicó el artículo “Un traductor más” en El Imparcial del 2 de julio de 1883. Fue amigo tan allegado de la familia que Benito Pérez Galdós le usurpaba su identidad para hacer llegar sus propias cartas a la escritora (Pardo Bazán 1978).
} 


\title{
Carta 2
}

\author{
Maison Crimault \& Cíe, Produits Chimiques et Pharmaceutique \\ Bureaux, 8, rue Vivienne, Paris 8 \\ Rigaud \& Chapoteaut \\ Successeurs de Rigaud \& Dusart \\ Usine, 14, Rue des Huissiers, 14, Neuilly Sr Seine
}

Paris, 15 de diciembre de 1888.

Mi querida Emilia : hoy tenía intención de escribirle a $\mathrm{V}$. con el fin de felicitarles a todos $\mathrm{V}^{\mathrm{S}}$. con motivo de la próxima Pascua, calculando que más tarde no tendría tiempo, $y$ al ir a almorzar recibo su carta, que me explica su silencio prolongado. Siento mucho la causa y me alegro que el primogénito esté ya curado y tranquilizados todos $\mathrm{V}^{\mathrm{S}}$. No suponía yo enfermedad por el calderón que observaba su correspondencia de V., y sí que estaba V. en Madrid y ocupada en instalar su pied-à-terre?.

$\mathrm{Al}$ corriente de las impresiones de sus libros y deseando que vean la luz y lleguen a esta su casa para devorarlos. Mucho me satisface que haya enmienda en mi prosa, y que lea V. mis artículos. Juncos ${ }^{\mathrm{IO}}$, que los paga, me los alaba mucho y me dice que en su tierra puertorriqueña producen muy buen efecto desarrollando la afición a los buenos libros franceses, lo que prueba que el lector me escucha, lo que ya es algo.

Acepto la presentación de Don José Lázaro Galdiano, a quien estimo y considero como amigo de veras, ya que lo es de V. Y vamos ahora con todo lo relativo a la Revista: La España Moderna. El título me gusta, sin restricción. Como de todo lo demás no sé nada, ni de forma ni de fondo, no puedo dar mi parecer. Lo que sí le diré a V. es que la revista modelo para mí es la inglesa y no la francesa ${ }^{\text {II; }}$ que tengo la preocupación de que no servimos para hacer revistas los que somos de raza latina; pero como V. estará al frente ${ }^{\mathrm{I} 2}$ y del prodigioso cerebro de V. puede esperarse todo, yo no dudo que salga la hoja tal como sería apetecible, con trabajos amenos, notables e interesantes en filosofía, ciencias, artes, historia, etc.

Creo que debería $\mathrm{V}$. poner su nombre al frente, pues tiene suma importancia para el éxito y la venta. Claro que le cae a $V$. encima una responsabilidad que no tiene

\footnotetext{
9 En estas fechas Emilia Pardo Bazán pasaba cada vez temporadas más largas en Madrid, por lo que residió temporalmente en la calle Serrano, 68, $3^{\circ}$ izquierda. En 1890, su madre adquirió un piso en la calle de San Bernardo, 37, pral, donde fijó su residencia de invierno en la capital.

Io Manuel Fernández Juncos (Tresmonte-Ribadesella, 1846 - San Juan, Puerto Rico, 1928). Periodista, poeta y pedagogo español que vivió en Cuba y en Puerto Rico, donde contribuyó a la fundación de instituciones diversas en favor de la educación del pueblo. Fundó varios periódicos, entre ellos El Buscapiés y La Revista Puertorriqueña, en la que escribía asiduamente Leopoldo García Ramón. Presidió el Partido Autonomista Histórico y la Liga de Republicanos Españoles en Puerto Rico y llegó a ser el Primer secretario electo de aquella nación, en 1897.

II Se refería a las prestigiosas revistas: La Revue de Deux Mondes, frente a The Edinburgh, The Quarterly, Blackwood's o The London.

${ }^{2}$ Nota añadida al margen por Doña Emilia: No le decía nada de estar al frente sinó de auxiliar y le preguntaba su opinión.
} 
contentándose con ser oculta inspiradora, pero un nombre desconocido al frente de una publicación nueva no da ninguna garantía al lector.

Si es serio, si hay dinero, si la Revista tiene fondos para luchar y sostenerse contra viento y marea, suceda lo que quiera, ponga $\mathrm{V}$. su nombre en la cubierta (el color de ésta también muy importante), pues lo desastroso sería que una Revista dirigida por V.; feneciese a los 6 meses de nacida. 7 a 10 trabajos de plumas de primera; bueno, y mejor pagándolos, lo que es digno; pero, ¿qué trabajos? Ahí está la cuestión. Hay tan pocos que sepan lo que ha de ser un trabajo de revista. En fin, lo repito, V. está con la sartén en la mano, y es mi única esperanza.

Mi colaboración. Si V. la quiere, naturalmente está a su disposición. Pero vamos por partes.

$\underline{\text { Anonimia }}^{\mathrm{I} 3}$. No estoy de acuerdo con V. si se trata de crítica literaria. O el crítico gusta o no (sic). Si no gusta, el único recurso es cambiarlo. Si gusta, el lector no se cansa de ver el mismo nombre, al contrario, lo busca, y aun en la prensa política, lo que no se firma aquí es lo político, pero lo artístico sí, y el Temps se vende muchísimo más el lunes sólo porque Sarcey firma la crítica teatral ${ }^{\mathrm{I} 4}$. Por lo demás, no tuerzo el gesto ni poco ni mucho; en esto no me ha calado V. Creo empero haberle dicho que la opinión del público me importa tres pitos y sólo estimo la de las personas que saben leer y apreciar. Tanto es así que, si no fuera por la especie de coquetería que entraña, ni las novelas firmaría. Como V. comprende, si mis artículos salen bien y gustan, el gremio literario sabrá perfectamente quién los escribe y eso me basta. Estoy pues dispuesto á escribir sin firmar.

${\text { Precio }^{15}}^{15}$. El más módico, son 50 francos. Pero vaya por 30, pues lo capital no es el importe sino que no sea gratis. En lo que no estoy conforme es en que varíe y sea hoy uno y otro mañana, y no por el interés. Voy á explicarme. Dice V. «Figúrese V. que le convengan una croniquitas muy cortas» ${ }^{\mathrm{I}}$. Yo soy lo más servicial del mundo, pero en letras más independientes que el aire. No acepto pues, orden alguna, y quedo árbitro de escribir cuanto sea necesario. Como tengo conciencia literaria, y por las Revistas de la Puertorriqueña puede V. saberlo, siempre daré más que lo pagado. Por añadidura, tampoco sé escribir sobre lo que quieren sino sobre lo que se me ocurre, - y esto reza también con los artículos sueltos, de fondo, - y en fin no puede tampoco decirme, ni es necesario, de esto diez líneas, de aquello, cuarenta. Por esto creo que $\mathrm{V}$. debe fijar:

$1^{\circ}$ La dimensión ordinaria de las crónicas, -tantas cuartillas- y en libro de 200 páginas, de 10 a 12 me parece lo menos. En este cuadro, si he de ver diez asuntos, doy

\footnotetext{
I3 Nota al margen de Doña Emilia: "Le hablaba yo de una sección parisiense anónima”.

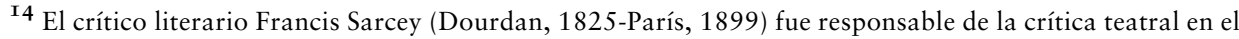
periódico Le Temps. Cada lunes, desde 1867 hasta 1899, ofrecía a sus lectores sus juicios y valoraciones de las obras que se representaban durante la semana en los teatros parisinos. Por ello fue una autoridad en la materia bastante temida por dramaturgos, compañías y empresarios.

I5 Nota al margen de Doña Emilia: "Para estas crónicas anónimas le ofrecía 30 fr”.

${ }^{\text {I }}$ Nota al margen de Doña Emilia: "Esto se lo decía porque propende a escribir larguísimo”.
} 
la plaza preferente al que lo merezca, y siguen los otros por orden de importancia.

$2^{\circ}$ Los puntos que ha de tratar esa crónica ó sección. Los enumera V. uno a uno; todos los acepto de antemano, por especiales que sean, sin miedo a decir un disparate, salvo la política. Abomino el género, soy bastante acerbo en él y tengo ideas que no cabrían en revista dirigida por $\mathrm{V}$.

$3^{\circ}$ Lo que debo evitar $^{\mathrm{I} 7}$; no sé contar sin apreciar, (a menos de novelar) y como soy la sinceridad en persona, no digo lo que no pienso. Ungüento,...para los granos. Consiento en callarme, en resbalar, no en decir lo que no sienta, ni no firmando, pues es ¡qué no puedo! ${ }^{18}$ Una vez sabido lo que sea, escrupulosamente me atendré a ello. Si hay crítica literaria, engorro será hablar dos veces de Zola, por ejemplo, una en la Puertorriqueña y otra en La España Moderna. Por esto quisiera que los artículos que me reservase $\mathrm{V}$. para el cuerpo de la Revista, con firma o sin ella, fuesen para los libros de los escritores de primera, Zola, Goncourt, Daudet, Maupassant ${ }^{\mathrm{I}}{ }^{9}$, etc.

Respecto de libros, no puedo hablar sino de los que me dan los editores, porque hay tomos como los Cuentos judíos de Sacher-Masoch ${ }^{20}$ que valen 30 francos y no puedo comprarlos. No firmando, tampoco puedo perdirlos para La España Moderna; tendrán pues que pasar algunos libros, dignos de ser descritos, sin que los mencione ó me concrete á indicar su aparición, sin juicio crítico. Especifíquelo V. todo, para estar de acuerdo, y fije $\mathrm{V}$. cuando hay que comenzar; el día en que mis trabajos deben llegar a Madrid, y dirigidos á quien y á que señas y todo irá bien. En cuestión metálica, precio, pago, etc. como V. quiera; lo que yo deseo es estar con V. contribuir á una obra interesante y nada más.

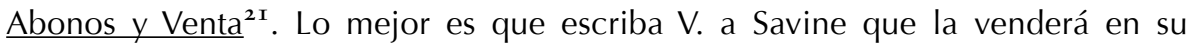
librería ${ }^{22}$, y en los kioskos él también se puede entender. Yo no tengo tiempo para ello, ni vocación. El negocio me apesta. Ya mandaré a Antonio a preguntar el cómo se arregla esto. Enviará V. un número a Labadie Lagrave ${ }^{23}$, del Figaro, que se ocupa a menudo de las "Revistas extranjeras" y bueno será que hable de ésa.

\footnotetext{
I7 Comentario al margen de D. Emilia: "Porque es muy libre pensador y yo quería evitar sus crudezas".

I 8 Precisamente Emilia Pardo Bazán temía la excesiva sinceridad de Leopoldo García y quiso encauzar y reducir sus colaboraciones a las rúbricas sobre crónicas diversas de la vida en París.

${ }^{\text {I9 }}$ Doña Emilia, pese a su amistad, no satisfizo la demanda de su amigo. Su artículo se centró, como ya se ha dicho, en la presencia de la literatura francesa en España, en la sección bibliográfica.

20 Sacher-Masoch, Leopoldo, Contes juifs, récits de famille, París, Quantin, 1888.

${ }^{2 I}$ Comentario al margen de D. Emilia: "Esta indicación puede ser útil”.

22 En 1882, Albert Savine trabajó de lector para la parisina libreria de E. Giraud, "La Nouvelle Librairie parisienne”. Tras su adquisición, la trasladó a la rue des Pyramides. Allí publicó un amplio elenco de obras francesas -las más influyentes de la época-y gran variedad de obras extranjeras noruegas, inglesas, portuguesas y, en particular, algunas de ellas traducidas por él mismo.

23 André-Gaston Labadie-Lagrave, quien firmaba G. Labadie-Lagrave, escribía puntualmente en Le Figaro Littéraire una crónica titulada "Revues de l'étranger" a la que alude Leopoldo García Ramón. Aunque no se conservan los números correspondientes a las fechas de esta carta, sí hemos localizado reseñas de los artículos de La España Moderna entre 1907 y 1909 en la sección "Lectures étrangères".
} 
No sé nada de lo de Galdós. No salgo de mi Revista y mi novela. Dígame V. lo ocurrido $^{24}$.

Y sin tiempo para más, y esperando su contestación, cómanse $\mathrm{V}^{\mathrm{S}}$. el pavo con toda felicidad, y un abrazo de Constance ${ }^{25}$.

Suyo affmo.

Leopoldo García

Nota al pie de Doña Emilia: Le digo en resumen que espere noticias desde Madrid. Podemos tener la necesidad de que envíe a tiempo lo que se necesite.

${ }^{24}$ Se refiere al célebre affaire amoroso de Doña Emilia con José Lázaro, que Galdós -compañero sentimental de la escritora a la sazón- supo por las indiscreciones de Narcis Oller (Thion, 2003).

25 Esposa de Leopoldo García Ramón. 


\section{Carta 3}

Maison Crimault \& Cíe, Produits Chimiques et Pharmaceutique

Bureaux, 8, rue Vivienne, Paris 8

Rigaud \& Chapoteaut

Successeurs de Rigaud \& Dusart

Usine, 14, Rue des Huissiers, 14, Neuilly Sr Seine

Paris, 23 de Febrero 1889.

Mi querida Emilia: su carta de V. fechada el 19 llega a mis manos hoy, día de la fecha, y lo apunto para que conste que respondo correo por correo.

Necrología. Bien; su aprobación de V. me sabe a lo más dulce que sea posible imaginar. Basta con esto para mi completa satisfacción, pero deseo que agrade al público, si no por mí por la Revista.

Contabilidad. Para no formar nuevas cuentas páguele V. a Blaser la primera libra de té; la segunda y los 50 francos del amigo Sr. Lázaro, me los puede V. remitir por cheque sobre el Crédit Lyonnais.

Cuestión de té. Si cree V. necesitar cierta cantidad de este producto, tal vez convendría comprar 6 libras pues las sacaríamos a 6 francos la libra (sin el porte); remito circular sobre esto suplicándole a V. me la devuelva con sus instrucciones. Si se decide $V$. por esta compra, me mandará 36 francos y el valor de 2 paquetes postales 2,50, en total: $\underline{38,50 \text {. }}$

Para el Sr. Lázaro. Mil gracias por el ofrecimiento de las $\operatorname{tapas}^{26}$ y de la mar, al cual corresponderé como pueda, y la buena voluntad puede mucho.

Me va a parecer un sueño cobrar 50 fran $\cos ^{27}$ por un artículo literario publicado en España, y admiro la potencia ${ }^{28}$ de este señor que convierte los sueños en realidades. Me alegro que el público responda y creo que responderá en América, siendo el Sr. Lázaro tan buen administrador como colijo por lo que $V$. me dice.

La cuestión de los anuncios es difícil. Ya sabe V. que estoy ocupado todo el día en casa de Rigaud y por la noche con la literatura. El tiempo material me falta. Haciendo un esfuerzo a favor de la publicación que me interesa y deseo se levante a la altura que merece, podría mandar circulares, -remitiéndomelas impresas el Sr. Lázaro, a quien envié un modelo; - pero esto no basta, es preciso visitar a toda esa gente, y ¿cómo y cuándo puedo hacerlo yo? Lo preferible me parece dirigirse a las Agencias que, mediante 20 \% darán anuncios, o encontrar una persona que aquí se

\footnotetext{
26 Para promocionar la revista José Lázaro regalaba seis tapas rígidas gratuitas para encuadernar los diferentes números a los suscriptores en 1889.

${ }^{27}$ La España Moderna remuneraba de manera jerárquica a sus colaboradores. Leopoldo recibió la máxima retribución frente a personalidades como Morel Fatio, que sólo percibía 30 francos -la suma media normal- por sus textos.

28 Galicismo: el poder, la capacidad.
} 
ocupe de ello más exclusivamente, lo que bien mirado es difícil. Suponga V. que me dan los anuncios 1000 francos y es bastante dar, pues el administrador aquí ganaría 2000 francos al año. No basta para ocuparse sólo de ese periódico; y si el corredor se ocupa de otros, mejor dirigirse a Saavedra o la Agencia Havas ${ }^{29}$.

Yo tanteé a Saavedra y me dijo que de una Revista sola se ocuparía con gusto. Puedo hablarle otra vez cuando el Sr. Lázaro me diga lo que desea; de todos modos, una carta se V. a Saavedra no estará de más. Respecto de esta casa, cuando un viajante que tenemos por España Ilegue a Madrid, y será pronto, recomendará la Revista y se le darán anuncios probablemente, siempre que nos reserven la página cara al texto. En resumen yo haré cuanto pueda; lo principal es que el Sr. Lázaro me esponga (sic) sus miras, con números al canto.

Un abrazo de Constance que insiste en saber cuándo vendrá V.

Un deseo mío, de los vivos, sería tener algo de su madre de V. para colgarlo en mi despacho. Un dibujo me basta, es sólo el gusto de poseer su firma. ¿Quiere V. transmitirle mi petición? $3^{\circ}$.

Queriéndola y hasta otra

Leo (rúbrica)

¿Hablará la revista de la novela de Pereda? ${ }^{31}$ Aún no la he leído.

\footnotetext{
${ }^{29}$ La actual Agence France-Presse, históricamente conocida como la Agencia Havas, fue fundada en 1835 por un traductor y publicista parisino, Charles-Louis Havas. Dado su rápido crecimiento e implantación, la agencia gozaba de la exclusividad en el uso del telégrafo en Francia. La imaginación y eficacia de sus dirigentes les impulsó a no derrochar cualquier recurso, como fue la célebre transmisión de informaciones financieras de la bolsa de Londres mediante palomas mensajeras. Por su presencia en las guerras de Crimea (1854) y de Italia (1859) Havas alcanzó un importante desarrollo internacional. Entre 1865-1879, diversificó sus actividades al fusionarse con la Societé Generale des Annonces y combinar la explotación de ambos servicios por los periódicos de provincias; de ahí que Leopoldo García les sugiriese sus servicios.

30 Las aficiones a la pintura de la Condesa madre, Amalia de la Rúa Figueroa y Somoza son conocidas. En la Casa-Museo de Emilia Pardo Bazán todavía se conservan algunos de sus cuadros.

3 I Yxart, José (mayo 1889): “Notas Bibliográficas. La Puchera por José María de Pereda”, La España Moderna, 193-206.
} 


\section{BIBLIOGRAFÍA}

Alonso, Cecilio (2006): Índices de Los Lunes de El Imparcial (1874-1933), Madrid, Biblioteca Nacional.

Álvarez Sereix, Rafael (10 de agosto de 1886): "Nota a «Cartas de París»", Revista Contemporánea, 155-167.

Asún, Raquel (1979): El proyecto cultural de La España Moderna y la literatura (1889-1914). Análisis de la revista y de la editorial, Tesis inédita, Universidad de Barcelona.

Asún, Raquel (1981-82): "La editorial de La España Moderna", Archivum, 31-32, 133-99.

Davies, Rhian (1997): "La Revista es mía y amicorum", Goya: Revista de arte, 261, 545-554.

Davies, Rhian (2000): La España Moderna and Regeneration: A cultural Review in Restoration Spain 1889-1914, Manchester, Manchester Spanish \& Portuguese Studies.

Escolar Sobrino, Hipólito (1989): "Don José Lázaro editor", Cuadernos para la Investigación de la Literatura Hispánica, 11, 7-20.

Faus, Pilar (2003): Emilia Pardo Bazán. Su época, su vida, su obra, Coruña, Fundación Barrié de la Maza.

García Ramón, Leopoldo (1884): Seres humanos (estudios de mujer), [con una carta-prólogo de Emilia Pardo Bazán], París, Biblioteca de la Europa y América.

García Ramón, Leopoldo (1886): Dos amores, París, A. Lanier.

García Ramón, Leopoldo (abril de 1889): "Escritores americanos. Don Juan de Montalvo", La España Moderna, 99-121.

García Ramón, Leopoldo (febrero de 1889), "Notas bibliográficas. La novela española en Francia", La España Moderna, 202-207.

Ozaeta, Ma Rosario (2007): “En torno a la traducción de un relato de Maupassant: Sur l'eau", Anales de Filología Francesa, 15, 205-220.

Pardo Bazán, Emilia (14 de febrero de 1894): "Seres humanos", El Día.

Pardo Bazán, Emilia (1978): Cartas a Galdós, edición de Carmen Bravo Villasante (ed.), Madrid, Turner.

Pardo Bazán, Emilia (25 de abril de 1889): "Entre paréntesis. A una cara memoria", El Liberal, 1.

Pardo Bazán, Emilia (mayo de 1891): "Juicios cortos", Nuevo Teatro Crítico, 86-90.

Pardo Bazán, Emilia (diciembre de 1893): "Letras y libros", Nuevo Teatro Crítico, 286-290.

Pegenaute, Luis (2004): "La época realista y el fin de siglo" in Francisco Lafarga \& Luis Pegenaute (eds.): Historia de la traducción en España, Salamanca, Ambos Mundos, 397-478. 
Thion Soriano-Mollá, Dolores (2003): Emilia Pardo Bazán y José Lázaro Galdiano. Del lance de amor a la aventura cultural (1888-1914), Madrid, Ollero y Ramos, Fundación Lázaro Galdiano.

Thion Soriano-Mollá, Dolores (2011): "De nuevo con Edmond Goncourt y Emilia Pardo Bazán en eco", Las Literaturas europeas en España, Universidad de Barcelona, 509-528.

Villapadierna, Maryse (1983): La España Moderna, Thèse por le Doctorat, París, Sorbonne.

Villapadierna, Maryse (1984): “La España Moderna (1889-1914): éléments d’une revue culturelle sous la restauration", Danièle Bussy-Genevois (ed.): Typologie de la presse hispanique, Rennes, Université, 79-86.

Yeves Andrés, Juan Antonio (2002): La España Moderna. Catálogo de la editorial. Índice de las revistas, Madrid, Libris.

Zaravel (15 de mayo de 1891): "Notas sueltas", Revista Contemporánea, 243-245. 